\title{
Middle Chalcolithic expansion into the highlands of the north-central Taurus, south-western Cappadocia
}

Abdullah Hacar ${ }^{1, *}$, Murat Tektaş ${ }^{2}$, H. Simge Egeci ${ }^{3} \&$ Michael Johnson $^{4}$

Recent archaeological survey in south-western Cappadocia reveals Middle Chalcolithic expansion into the highlands, where there is no known evidence of earlier permanent settlement.

Keywords: Turkey, south-western Cappadocia, north-central Taurus, Middle Chalcolithic

\section{Introduction}

Since 2017, a survey has been underway in the north-central Taurus Mountains in southwestern Cappadocia. The project aims to collect data that will enable analysis of the cultural developments and transformations of the region from the Neolithic to the end of the Early Bronze Age. Our initial evaluation of Middle Chalcolithic material, which is the subject of this article, began with a re-evaluation of finds obtained by Aslihan Yener between 1987 and 1996 during a survey of the north-central Taurus (Yener 2000). At the lowest levels excavated inside Kestel Mine, and among the surface materials of the two settlements close to Kestel Mine (Çardacık-Karatepeler and Mahmatlı-Boztepe), Middle Chalcolithic finds were identified that are much more common in the western Cappadocian plateau. This raised several questions for further investigation. Primarily, what does identification of western Cappadocian Middle Chalcolithic cultural materials in the highlands of the north-central Taurus reveal about the cultural relationship between the two regions? Could this relationship be related to mining? And is there a possibility that mining activities began in the central Taurus during the Middle Chalcolithic period? In light of evidence for extractive metallurgy at the nearby sites of Köşkhöyük (level I) and Mersin-Yumuktepe (level XVI) during the Middle Chalcolithic, this possibility deserves serious consideration (Yalçın 2000; Öztan 2002).

\section{Western Cappadocia in the Middle Chalcolithic}

The most detailed information on the western Cappadocian Middle Chalcolithic has been obtained from the excavations of Güvercinkayası (Aksaray-Gülağaç) and Köşkhöyük (Niğde-

1 Department of Archaeology, Hitit Üniversitesi, Ulukavak Mahallesi, Adnan Özejder Caddesi, Çorum 19030, Turkey

2 Nigde Museum, Yukarı Kayabaşı, Dışarı Camii Sok 11, Nigde 51000, Turkey

3 Department of Archaeology, Dokuz Eylül University, Doğus Caddesi 207/M Tinaztepe Yerleşkesi, Izmir 35390, Turkey

4 Department of Near Eastern Languages and Civilizations, University of Chicago, 5828 South University Avenue, Chicago IL 60637, USA

* Author for correspondence (Email: abdullahhacar@hotmail.com)

(C) Antiquity Publications Ltd, 2019

ANTIQUiTY 93 372, e33 (2019): 1-7

https://doi.org/10.15184/aqy.2019.184 
Bor) (Öztan 2002; Gülçur 2004) (Figure 1). The well-preserved levels of Köşkhöyük I and Güvercinkayası I-II are dated to the Middle Chalcolithic (5200-4800 BC) (Gülçur 2012). Results from these two settlements and survey evidence indicate that radical changes had taken place in local societies during that period. This can be observed clearly in finds, choice of settlement location, building plans and pottery production, as well as subsistence economy. Most settlements were located on natural hills or slopes. The settlement plan of Güvercinkayası, revealed during excavation, with its fortification wall and two towers, suggests that security concerns had begun to dominate the character of the settlement (Gülçur 2004).

The buildings of Güvercinkayası and Köşkhöyük reflect very similar architectural layouts and location choices, while pottery production also shows extensive similarities, with black or dark burnished ware forming a major component of the assemblage. Vessels obtained from these different settlements are quite similar in terms of production technique and shape. Shiny black burnishing and naturalistic or symbolic reliefs (cattle, goats, deer, dogs, snakes and stylised horns or eyebrows/eyes) applied to the outer surface are characteristic of Middle Chalcolithic pottery (Öztan 2002; Gülçur 2004).

The study of the faunal remains of Güvercinkayası and Köşkhöyük reveals that the animal economy, once dominated by domestic sheep and goats, changed dramatically in the Middle Chalcolithic (Gülçur 2012; Meiggs et al. 2018). In addition, the results of the analyses of strontium isotopes from Köşkhöyük indicate that in contrast to Early Chalcolithic grazing patterns, pastures farther away from the settlement were used during the Middle Chalcolithic (Meiggs et al. 2018).

\section{Recent discoveries in the highlands}

The current survey was conducted on the southern margin of the Bor Plain and in the highlands of the north-central Taurus. In the first two seasons, important data were obtained to analyse Middle Chalcolithic social structures and lifestyles. Nine new Middle Chalcolithic sites were discovered, along with the three sites previously identified by Yener (Figure 1) (Yener 2000). All of these sites are located in the valleys or in the northern margin of the central Taurus.

Our survey results have revealed three different settlement types for the Middle Chalcolithic. The first is generally located in an elevated position on the edge of fertile plains. These sites were built over earlier Neolithic to Early Chalcolithic settlements, as seen at Köşkhöyük and possibly also Tepecik-Çiftlik, located in the north of our study area, and at Galhanehöyük and Bekçitepesi, located in the south margin of the Bor Plain.

The second and third settlement types clearly reflect Middle Chalcolithic expansion. They are generally located on naturally protected ridges at the edge of highland valleys (Figures 1-2). Aşrlıktepe, Dikmenhöyük and Hökeneztepe, discovered during our survey, and MahmatlıBoztepe and Çardacık-Karatepeler, discovered previously by Yener, are the second settlement type. These sites are located along a valley system, about 3-8km away from each other; they can be described as small settlements, with the largest being approximately $100 \times 80 \mathrm{~m}$. Architectural remains that may represent fortification walls similar to those at Güvercinkayası have been identified around most of the sites (Figure 3). Unlike the first site type, all of these settlements were new foundations, with the earliest remains dating to the Middle Chalcolithic. Furthermore, all these settlements were abandoned at the end of this period. These features suggest

(C) Antiquity Publications Ltd, 2019 


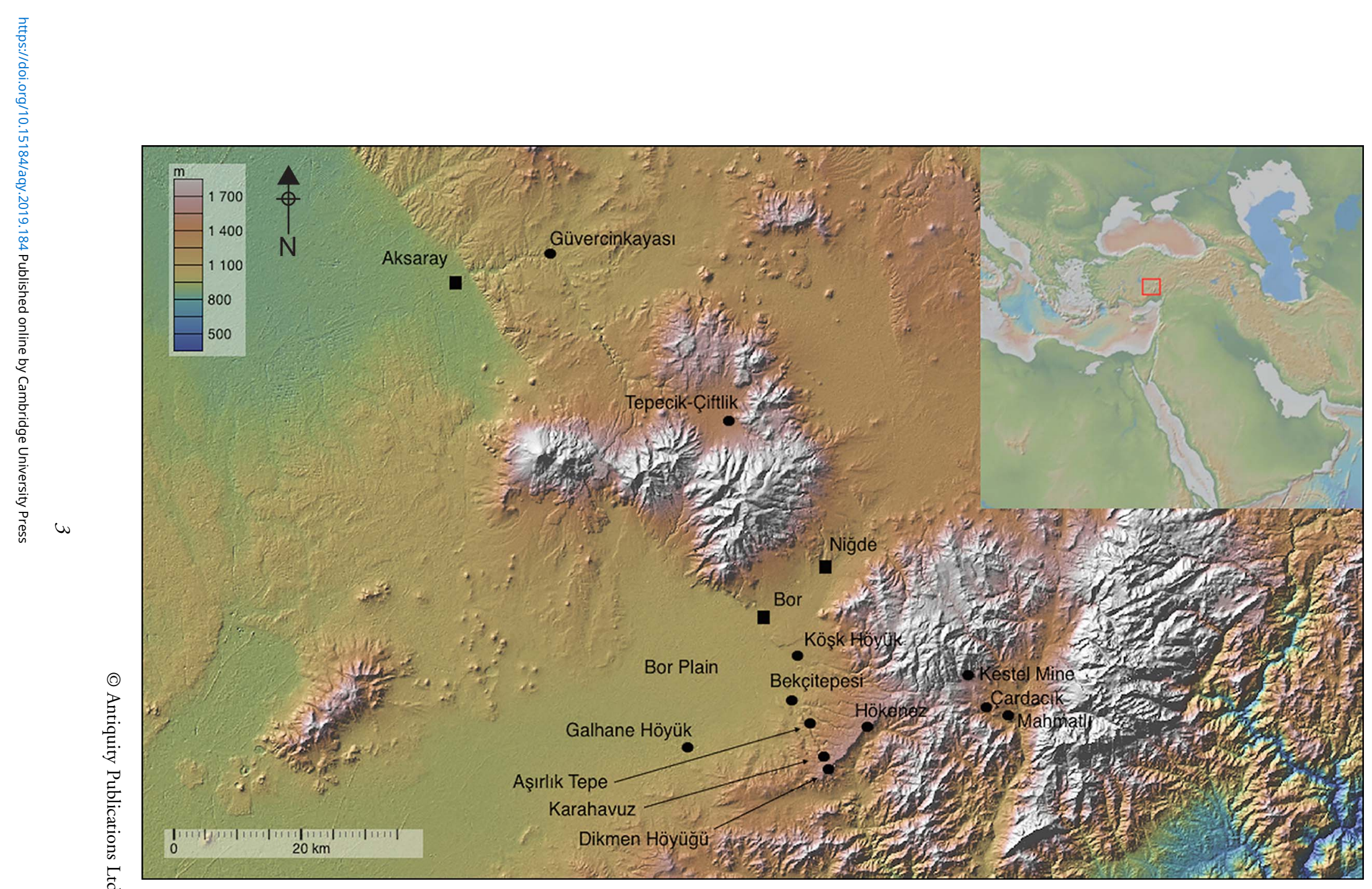

₹ Figure 1. Location map showing the sites mentioned in the text. 


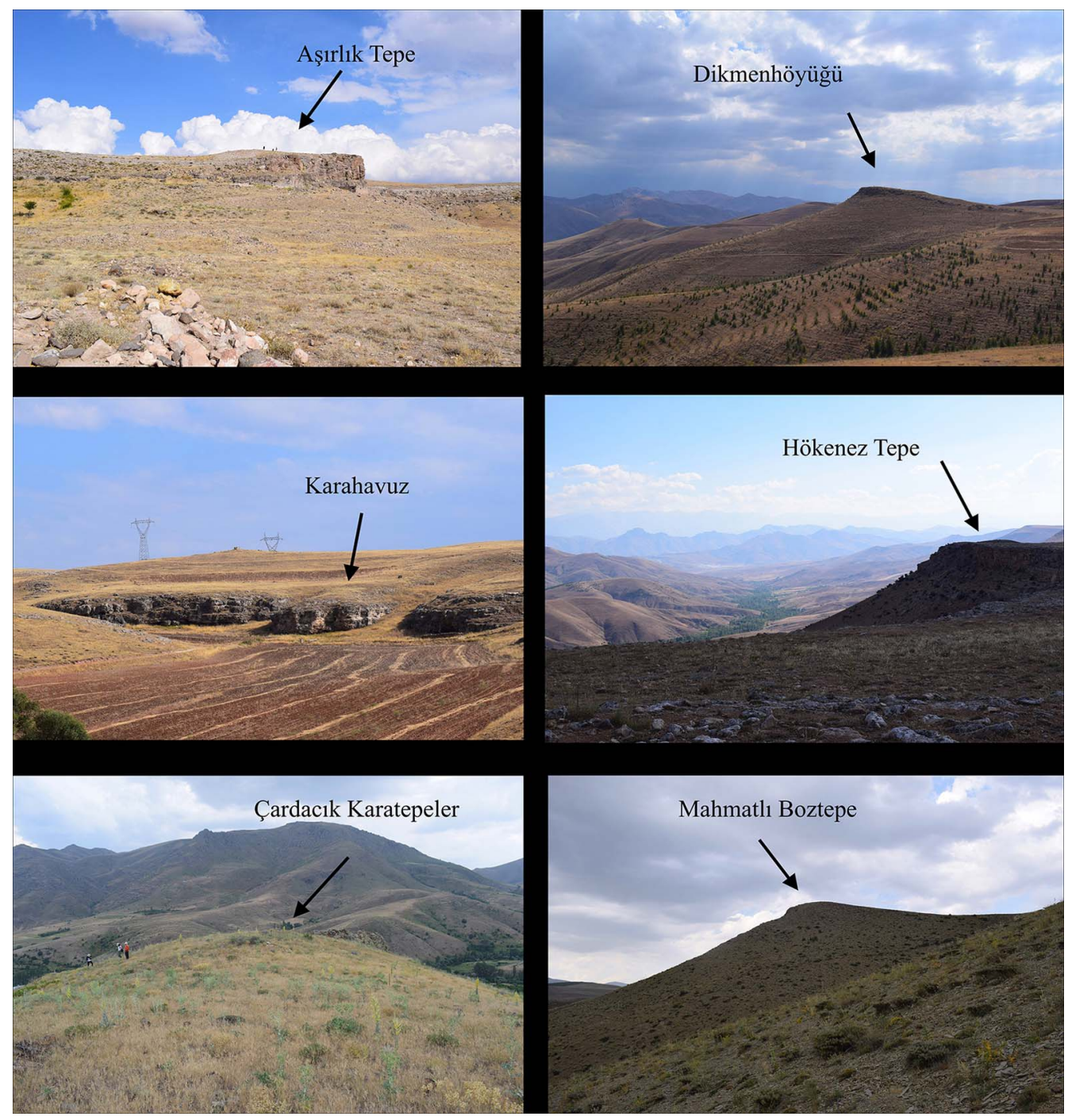

Figure 2. Middle Chalcolithic sites in the highlands (photographs by A. Hacar).

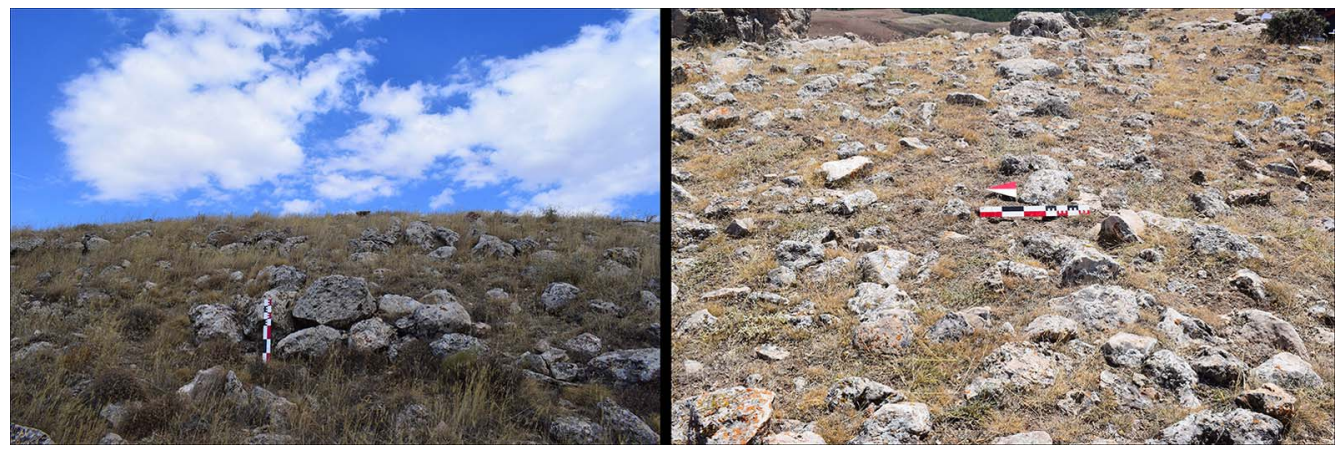

Figure 3. Architectural remains from Dikmenhöyü̈̆̈̈ (left) and Hökenez (right) (photographs by A. Hacar).

(C) Antiquity Publications Ltd, 2019 


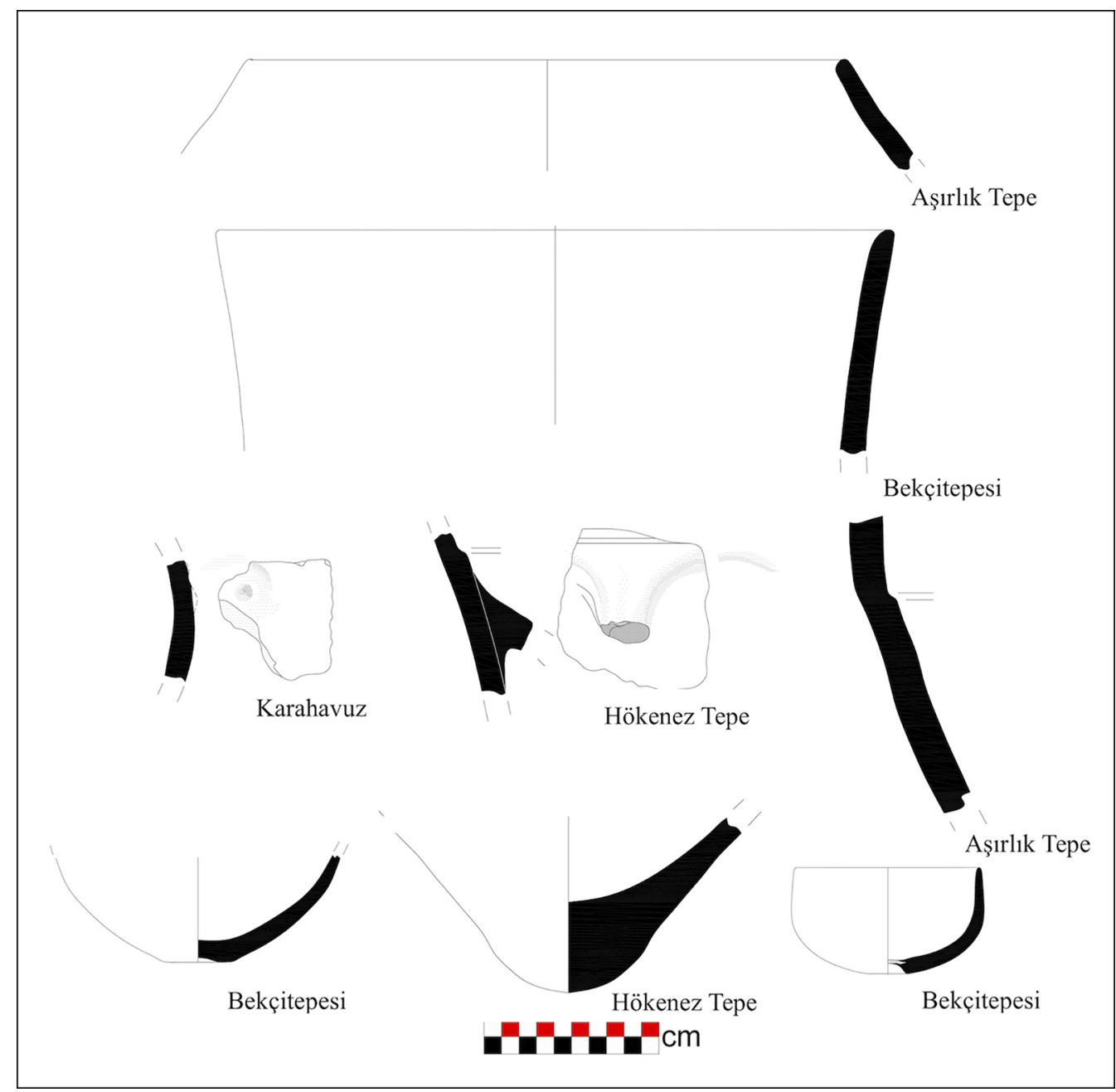

Figure 4. Example of Middle Chalcolithic pottery (drawing by A. Hacar).

a pattern of Middle Chalcolithic expansion into the highlands under a new socio-political structure that ultimately seems to have failed at the end of the period. On current evidence, we are not yet able to define this phenomenon clearly, however.

The third settlement type consists of seasonal camps with exclusively Middle Chalcolithic finds. Karahavuz, discovered during our survey, is among this type. The rather scant archaeological deposits were identified on a small ridge measuring $50 \times 30 \mathrm{~m}$ (Figure 2). Dairy produce was an important part of the Middle Chalcolithic subsistence economy; the identification of seasonal settlements may reveal more about the lifestyles of groups engaged in animal husbandry (Meiggs et al. 2018).

The majority of the pottery collected from all the settlements surveyed is black burnished ware. The production techniques and forms are similar to western Cappadocian examples that use grit, chaff and mica temper; reduction firing and shiny burnishing are also very

(C) Antiquity Publications Ltd, 2019 


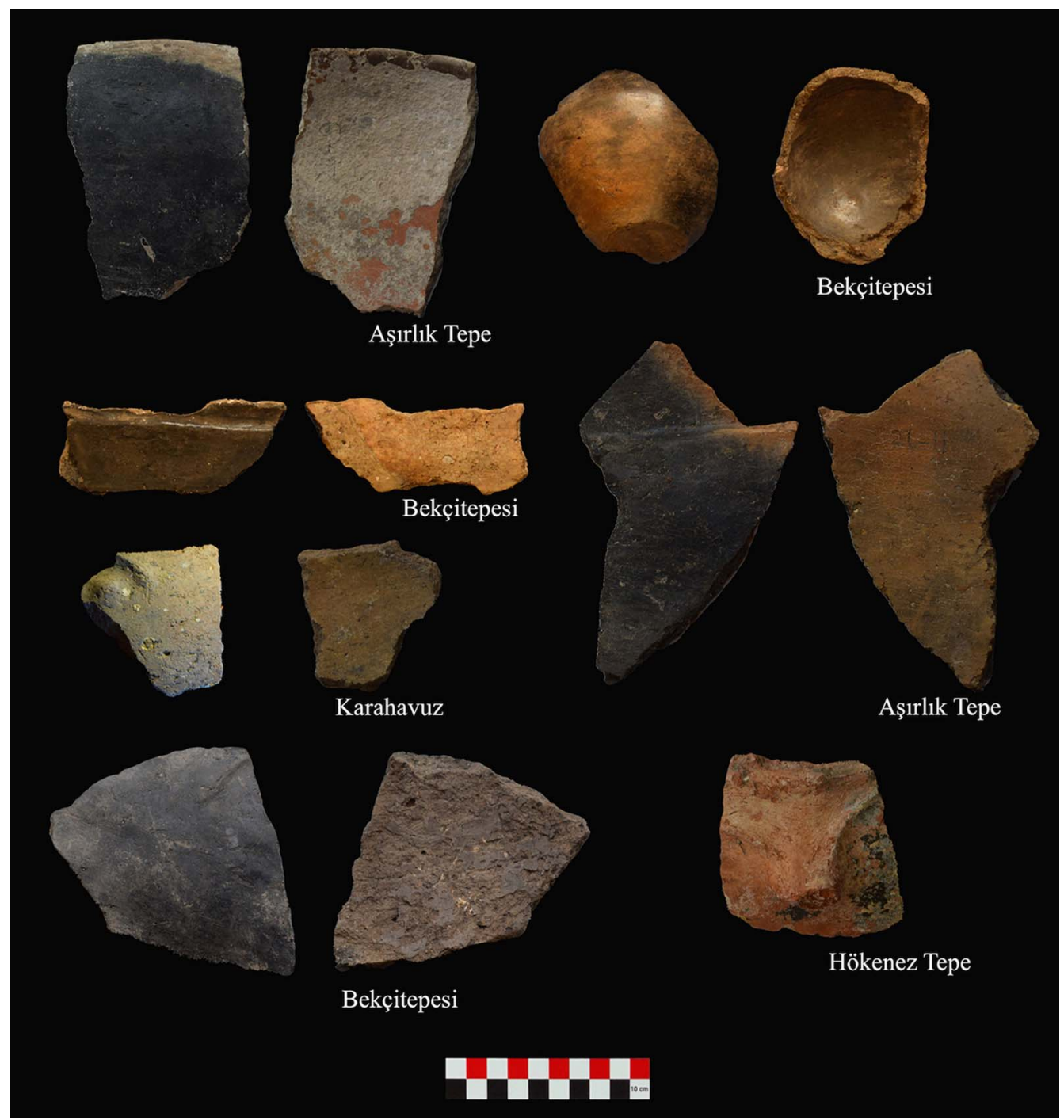

Figure 5. Fragments of Middle Chalcolithic pottery (photograph by A. Hacar).

common (Figures 4-5). Jars, particularly storage jars, have an important place in the pottery assemblage, with some having relief-decoration on the exterior surface.

Very limited finds that may be related to mining activities were recovered from the sites. Among them are stone tools and a fragment of fused material, which could be a piece of slag, found in Mahmatli-Boztepe. Considered in light of this region's long-term association with metallurgy, and pending further analysis, these latest data allow us to posit an earlier date for the beginning of mining in the north-central Taurus than previously recognised. This, in turn, suggests that changes in the subsistence economy in western Cappadocia, resulting in the establishment of highland settlements, may have been closely linked to the development of mining and metallurgy.

(C) Antiquity Publications Ltd, 2019 


\section{Future work}

In western Cappadocia, a new lifestyle was adopted at the beginning of the Middle Chalcolithic; this is evident through the presence of distinctive cultural materials. Middle Chalcolithic groups not only settled at pre-existing sites in the region, a practice which differed from that in use from the Neolithic to the end of the Early Chalcolithic, but also spread throughout the highlands to previously unoccupied sites. As this settlement pattern is becoming clearer, the survey data also shed light on the socio-economic and political structure of this culture. During subsequent surveys, we aim to collect data that will enable us to answer the following questions: what motivated the Middle Chalcolithic expansion? Was it related to a transhumance lifestyle or driven by early mining activities? Why do we see a move to more protected settlement locations? And finally, what are the characteristics of the dynamics, economy and political organisation of Middle Chalcolithic society?

\section{Acknowledgements}

This project is supported by the Hitit University Research Fund (FEF19001.17.006) with the permission of the Turkish Ministry of Culture. We are grateful to Aslıhan Yener, Sevil Gülçur and Fikri Kulakoğlu for their support.

\section{References}

GüıçUR, S. 2004. Güvercinkayası: the black-dark burnished pottery. A general overview. Tuba-Ar 7: 141-64.

https://doi.org/10.22520/tubaar.2004.0012

- 2012. The Chalcolithic period in central Anatolia Aksaray-Niğde region. Origini: Preistoria e protostoria delle civiltà antiche 34: 221-36.

Meiggs, D., B.S. Arbuckie \& A. Öztan. 2018. The pixelated shepherd: identifying detailed local land use practices at Chalcolithic Köşk Höyük, central Turkey, using a strontium isotope $\left({ }^{87} \mathrm{Sr} /{ }^{86} \mathrm{Sr}\right)$ isoscape, in A.R. Ventresca Miller \&
C. Makarewicz (ed.) Isotopic investigations of pastoralism in prehistory: 77-96. London: Routledge.

ÖZtan, A. 2002. Köşk Höyük: Anadolu Arkeolojisine Yeni Katkılar. Tuba-Ar 5: 55-72. https://doi.org/10.22520/tubaar.2002.0004

YaLçıN, Ü. 2000. Frühchalkolitische Metallfunde von Mersin-Yumuktepe: beginn der Extraktiven Metallurgie? Tuba-Ar 3: 111-30. https://doi.org/10.22520/tubaar.2000.0006

Yener, K.A. 2000. Domestication of metal: the rise of complex metal industries in Anatolia. Leiden: Brill. 